\title{
Contrôle Parlamentar da Administração Descentralizada no Direito Norte-Americano
}

\author{
ARNOLd WALD \\ Advogado no Distrito Federal
}

\author{
INTRODUÇÃO
}

\begin{abstract}
$\mathrm{O}$
direito administrativo norte-americano nos apresenta duas formas principais de descentralização: os independent establishments as government corporations.
\end{abstract}

Entre os estabelecimentos autônomos, encontramos, na maioria dos casos, comissões, cujo número de membros varia normalmente de 3 a 7 , e que, algumas vêzes, vg. na Interstate Commerce Commission ou na Federal Trade Commission, tem um corpo de auxiliares comparável àquele dos departamentos e repartições públicas. A tendência dominante no direito norte-americano é de utilizar a técnica das comissões sempre que a função exercida não é primordial e exclusivamente administrativa mas pressupõe a elaboração de normas regulamentares ou a prática da atividade para-judicial, ou seja, quando a missão do órgão é predominantemente deliberativa ou consultiva. (1)

Tais comissões foram criadas em grande número sob o impulso de necessidades de emergência em tempo de guerra. Outras todavia surgiram com a finalidade de fiscalizar as normas estaduais em matéria comércio e de bem estar social ou ainda de elaborar certos regulamentos que, pelo seu caráter técnico, dificilmente poderiam ser preparados no Congresso. As razões pelas quais tais funções foram entregues a estabelecimentos autônomos e nãơ aos departamentos públicos já existentes são as mais diversas. Algumas vêzes o govêrno não quis impôr a um ministério trabalhos ainda mais heterogêneos do que aquêles que já lhe competiam. Mas os motivos políticos é que ơcupam papel de primeiro plano. Os membros das referidas comissões são nomeados pelo Presidente e pelo Senado com mandatos longos, frequentemente de 7 anos, e que têm maior independência dơ que se fôssem submetidos a um departamento público. Alega-se ainda a superioridade de um órgão colegiado com representação bi-partidária sôbre o chefe de um departamento diretamente subordinado ao executivo. Assim também os estabelecimentos autô-

(1) FREDERIC A. QGG \& P. ORMAN RAY, Introduction to American government 9. ${ }^{a}$ ed., 1948, p. 471 . 
nomos são diretamente responsáveis perante o Congresso e sofrem um contrôle menos direto por parte do Presidente da República. E' aliás interessante notar que o chefe do executivo não pode demitir os membros de tais comissões salvo os casos de negligência ou ineficiência no exercíciơ do cargo. A questão foi apreciada pela Suprema Côrte norte-americana no caso Humphrey em 1935. William E. Humphrey era republicano e membro da Federal Trade Commission quando após uma divergência com o Presidente Roosevelt em 1933 foi sumàriamente demitido. Dois anos depois obtinha ganho de causa na justiça. A Suprema Côrte naquela ocasião reconheceu que a Federal Trade Commission não era um órgão executivo e fôra criada pelo Congresso com finalidade específica. Alegando o princípio da separação dos poderes, o judiciário garantiu assim a independência dos membros das comissões que, a partir daquela data, não mais poderiam ser demitidos pelo executivo por motivos políticos.

Diversas são as funções e os poderes exercidos pelos estabelecimentos autônomos. A United States Tariff Commission se limita a estudar os efeitos das leis fiscais, apresentando as suas conclusões a respeito em relatórios ao Presidente da República e ao Congresso. A maioria contudo tem simultâneamente funções judiciais, legislativas, administrativas, constituindo ainda ao mesmo tempo, órgãos informativos e consultivos. E' o que acontece com a Interstate Commerce Commission, a Federal Trade Commission, a Federal Communications Conmission e a Federal Securities and Exchange Commission. A Federal. Trade Commission combate a concurrência desleal. Seus membros têm um mandato de 7 anos, cada mandato começando em época diversa. Dos seus cinco membros, no máximo três podem pertencer ao mesmo partido político. A Interstate Commerce Commission, criado pelo Interstate Commerce Act de 1887 fiscaliza os transportes interestaduais interferindo na fixação dos preços das passagens. Constituem-na onze membros com mandatos longos, nomeados pelo Presidente com a assentimento do Senado. Seis dos membros no máximo podem pertencer ao mesmo partido político. As exonerações só podem ter lugar no caso de falta praticada pelo membrơ da comissão.

Vimos assim as principais funções e a razão de ser dos estabelecimentos autônomos (independent establishments).

Ao lado das comissões especiais e representando grau diverso de autonomia administrativa encontramos os government corporations. Inicialmente tais sociedades foram utilizadas sob a forma de economia mista com finalidades de política fiscal. A primeira sociedade em que o govêrno norte-americano teve participação foi o Banco dos Estados Unidos. Posteriormente o Estado adquiriu, em 1904, a Panama Railroad Company. Os poderes necessários para a criação de tais companhias foi deduzido da faculdade pertencente à União de tomar as devidas providências para incentivar o desenvolvimento da economia nacional. Com o início da primeira guerra mundial, foram criadas numerosas emprêsas públicas para evitar dificuldades que teriam surgido na realização de atividades ligadas ao esfôrço de guerra se tivessem sido executadas por departamentos do govêrno sujeitos a influências políticas. Em geral, a criação de tais emprêsas era previamente autorizada pelo 
legislativo e a sua organização era feita de acôrdo com as leis estaduais. Assim surgiram a United States Shipping Board Emergency Fleet Corporation, a War Finance Corporation, a United States Housing Corporation, a United States Spruce Production Corporation. Outras emprêsas todavia surgiram sem autorização expressa do legislativo. Emanaram de atơ do executivo baseado em autoridade própria embora tivesse o Presidente poderes especiais para utilizar ou criar qualquer emprêsa necessária à boa execução de determinada lei . Assim a United States Grain Corporation e a United States Sugar Equalization Board são resultantes das diretivas traçadas pelo Food Control Act. A United States Grain Corporation surgiu com um decreto do executivo de 14 de agôsto de 1917 , tendo sido a primeira emprêsa criada pelo executivo. A United States Sugar Equalization Board foi organizada de acôrdo com as leis estaduais pela Food Administration com aprovação do Presidente da República. Por outro lado, a War Trade Board of The United States Russian Bureau Inc. foi estabelecida em Connecticut de acôrdo com uma recomendação do War Trade Board aprovada pelo Presidente Wilson. Posteriormente numerosas emprêsas foram criadas por atos emanados do executivo. E' o caso, entre outros, do Export-Import Bank, da Commodity Credit Corporation, da Electric Home and Farm Authority Inc. e da Tennesse Valley Associated Cooperatives Inc. Nos diversos decretos criadores das emprêsas públicas, o executivo assinalava sempre as leis do Congresso em que se fundamentava para seguir a política de recuperação e desenvolvimento em que a criação da emprêsa apenas representava um dos meios utilizados. O Procurador Geral da República teve a ocasião de declarar que considerava o poder de utilizar as emprêsas públicas como método de executar as leis independentemente de qualquer autorização especial do legislativo como legítima atividade do exe. cutivo. Pouco importa pois que o Presidente da República tenha atendido a uma norma especial de determinada lei ou se tenha inspirado na política traçada pelo legislativo em certa matéria a fim de criar a emprêsa pública. E' uma faculdade que the pertence desde que não saia dos quadros da orientação geral seguida pelo Congresso.

Finda a guerra de 1914, a maioria das emprêsas públicas desapareceram por falta de objetivo. Assim se extinguiram a Emergency Fleet Corporation, a United States Grain Corporation, a War Finance Corporation, a United States Housing Corporation, United States Spruce Production Corporation, o Russian Bureau Inc.

Duas novas companhias foram todavia criadas antes da depressão econômica. Trata-se da Federal Intermediate Credit Banks que data de 1923 e da Iniand Waterways Corporation de 1924. Ambas foram devida e expressamente autorizadas pelo Congresso. Quanto à segunda companhia, é interessante assinalar que tinha como administrador o secretário de Estado em exercício na parte da guerra o que integrava de fato a emprêsa no sistema da política geral do govêrno embora mantivesse a sua devida autonomia.

Novo impulso foi dado à government corporation na administração de Hoover com a Reconstruction Finance Corporation e a Home Owners' Loan Corporation. Mas foi com o New Deal que "ocurred a mushroom growth of governamental corporations designed for administrative, fiscal, reliet and re- 
constructive purposes". (2) Diversas emprêsas foram criadas por leis especiais do congresso e outras por atos do executivo para alcançar finalidades determinadas por leis.

A partir de março de 1933 surgiram a Federal Farm Mortgage Corporation, a Federal Prison Industries Corporation, a Federal Savings and Loan Insurance Corporation, a Electric Home and Farm Authority Corporation, a Tennessee Valley Authority, a Regional Agricultural Credit Corporation, a Central Bank for Cooperatives, a Commodity Credit Corporation, o primeiro e o segundo Export-Import Banks, a Federal Credit Union etc...

Em 1936, existiam nos Estados Unidos cêrca de noventa emprêsas públicas.

Já naquela época surgiram numerosos problemas legais ligados à existência e à atividade das emprêsas públicas. Perguntou-se se as emprêsas públicas deveriam estar submetidas às normas ordinárias referentes às sociedades anônimas. Indagou-se se poderiam acionar ou serem acionadas em juízo. Se deveriam ter as mesmas condições preferenciais em matéria contratual que os departamentos administrativos. Até que ponto poderá haver interferência da legislação estadual em relação às emprêsas públicas federais. E qual a situação fiscal dessas emprêsas. E qual sua posiçãơ como devedor. Serão sujertas. à execução dos seus bens ou terão algum tratamento especial?

Já vimos pelos próprios nomes das diversas emprêsas o campo amplíssimo de atividades a que se destinam, abrangendo o desenvolvimento econômico de regiões atrazadas, (Tennessee Valley Authority) a construção de prédios de aluguel barato (Public Works Emergency Housing Corporation), procurando assegurar os depósitos bancários (Federal Deposit Insurance Co1poration) facilitando empréstimos à agricultura (Regional Agricultural Credit Corporation), ou exportações e importações (Export-Import Banks), etc.

As suas atividades vão desde a defesa nacional até a expansão do comércio e o desenvolvimento da agricultura e a contribuição ao bem estar social.

A jurisprudência e a doütrina norte-americana reconheceram que:

"Corporations are among the means which the congress may utilize in the exercise of federal powers. But in line with the principles above stated, each government corporation created or operated by the federal government must accomplish objects entrusted to the federal government and must bear a reasonable relation to some power or powers delegated to the federal government. (3)

E' na realidade uma nova interpretação ou melhor uma interpretação num novo campo - que é o das government corporations - da decisão McCulloch v. Maryland, renovada em 28 de novembro de 1934 acordão referente ao caso Ashwander v. Tennessee Valley Authority.

(2) MAURICE S. CULP, Creation of government corporations by the national government, in Michigan Law Review, fevereiro de 1935, vol. 33, n. $0^{\circ}$, p. 474.

(3) Artigo citado na nota supra, p. 490. 
Com a última guerra mundial, mais de vinte novas emprêsas públicas foram criadas. Citemos, entre outras, a Metals Reserve Company, a Rubber Reserve Company, a Defense Plant Corporation, a War Damage Corporation etc...

Existem também sociedades anônimas pertencentes aos Estados. $\mathbf{E}^{*}$ o caso do Port of New York Authority, sociedade da propriedade dos Estados de Nova Iorque e New Jersey. Também são states corporations as universidades de Michigan, Minnesota e Idaho e a North Dakota Mill and Elevator Association.

A administração das emprêsas públicas não obedece a normas uniformes. A emprêsa do Estado de Norte Dakota por exemplo era administrado por uma Comissão Industrial com poderes amplos que incluía o governador, o procurador geral do Estado. Os outros membros da Comissão eram eleitos pelo povo e sujeitos ao recall. A única autoridade que podia examinar as contas da emprêsa era o fiscal do banco do Estado que era nomeado e demissível ad nutum pelo governador.

A Tennessee Valley Authority é dirigida por um conselho diretor nomeado pelo presidente da República com a aprovação do Senado por um prazo de nove anos. A T. V. A. adota integralmente o sistema do merecimento.

O Federal Reserve Board é composto de sete membros com mandatos de quatorze anos, nomeados pelo Presidente da República com aprovação do Senado, devendo representar Estados e interêsses econômicos diversos, como por exemplo a agricultura, o comércio, a indústria.

A Reconstruction Finance Corporation criada em 1932, atendendo a mensagem do Presidente Hoover, tem um conselho diretor de 7 membros dos quais 4 são nomeados pelo Presidente da República com a aprovação do Senado.

Vemos pois o caráter sui generis da direção de cada emprêsa cuja estrutura depende normalmente da lei ou do decreto que a criou e já traçou as linhas gerais da sua estrutura administrativa. Na maioria dos casos, as nomeações dos diretores são por prazos longos, dependendo de indicação do Presidente da República e aprovação do Senado, só podendo haver demissão com justa causa. E' o mesmo princípio que se aplica aos membros das comissões como já tivemos o ensejo de ver.

Três razões principais militaram para a criação das emprêsas públicas nos Estados Unidos:

1. ${ }^{\circ}$ Facilitar o crédito em épocas de crise para permitir o restabelecimento do equilíbrio econômico (Reconstruction Finance Corporation).

$2^{\circ} .^{\circ}$ Liquidar certos problemas de emergência ligados à segurança nacional, como, por exemplo, as pesquisas sôbre a bomba atômica e o uso pacífico da energia atômica.

$3^{\circ}$ ) Dever o Estado exercer certas atividades comerciais que pela sua extensão e pela ausência de lucros ou pelo caráter remoto dos benefícios auferíveis não poderiam ser realizadas por particulares como teria sido o caso da 
Panama Railroad Company, da Inland Waterways Corporation e da Tennessee $V$ alley Authority, empreendimentos que não tem caráter comercial mas atenderam a fins políticos, econômicos e sociais.

O direitơ norte-americano abrange algumas vêzes as sociedades de economia mista num conceito amplo de government corporations. A bơa técnica é no sentido de distinguir as duas expressões como o faz aliás Leonard White assinalando que nas emprêsas públicas não há participação de capitais privados. "A análise das emprêsas públicas, escreve o jurista norte-americano, não nos revela um tipo simples e uniforme de estrutura. Elas variam no método de constituição, nas suas relações com a estrutura administrativa central, no grau de autonomia, na fonte dos seus capitais e na sua organização interna. Não existe uma definição de emprêsa pública geralmente aceita". (4)

O caráter singular de cada emprêsa se explica aliás pela sua função precípua, pela flexibilidade de que deve fazer prova. Cada lei ou cada decreto concebe uma estrutura diversa, quadros determinados em que devera se desenvolver a atividade da emprêsa de acôrdo com as necessidades a que corresponde e os imperativos a que deverá atender.

Reconheceu-se sempre que a superioridade das emprêsas públicas sôbre os departamentos administrativos ou repartições públicas pròpriamente ditas, completamente integradas no serviço público e sujeitas às suas normas, consiste justamente na flexibilidade e na eficiência comercial das corporations. São as chamadas liberdades em relação às normas do govêrno sôbre empréstimos e gastos, liberdade quanto ao sistema de contabilidade, liberdade de contratar sem os limites impostos pela concorrência pública, liberdade em relação às normas do serviço civil ou seja do sistema do concurso.

Os autores norte-americanos catalogaram da seguinte maneira as vantagens que a emprêsa pública oferece:

1. $\left.{ }^{\circ}\right)$ Autonomia financeira.

2..$^{\circ}$ Direito de obter e fazer empréstimos.

3. ${ }^{\circ}$ Liberdade de reger-se pelos seus estatutos e de estabelecer normas próprias para regulamentar „a situação dos seus funcionários, as compras da sociedade, etc.

$4^{\circ}$ ) Possibilidade de ter um sistema próprio de contabilidade, de transigir e fazer acordos, de processar e ser processado.

$5^{\circ}$ ) Descentralização regional e autonomia local.

Até 1935 , as emprêsas públicas tiveram nos Estados Unidos as chamadas 3 liberdades que consistiam respectivamente em não prestar contas ao Bureau of the Budget e ao Congresso, na isenção das normas e processos do civil service, (́sistema de concurso e de promoção) e na isenção da regulamentação legal estabelecida para as compras e os contratos realizados por entidades de direito público (sistema da concorrência pública).

(4) LEONARD WHITE, Introduction to the study of public administration, 3. a edição 1951, p. 119. 
Vemos que durante certo período a única interferência do contrôle parlamentar em relação às emprêsas públicas se verifica no exequatur à nomeação dos seus diretores por parte do Senado após indicação pelo Presidente da República.

A doutrina, todavia condenou as government corporations quando não entrosadas num ministério, considerando que não havia suficiente coordenação entre as atividades da emprêsa e a política geral do govêrno. A importância de um trabalho harmônico das diversas entidades estatais é assinalada pelos publicistas norte-americanos. Não basta, dizem êles, que a nomeação dos diretores da emprêsa dependa do Presidente da República. E' preciso integrar a emprêsa pública num ministério ressalvando todavia simultâneamente a autonomia, nomeando por exemplo o secretário de Estado pára o cargo de presidente da companhia. O que não é possível é que, após a nomeação dos seus diretores com mandato relativamente longo, a emprêsa possa ter uma política própria não integrada no sistema do govêrno.

\section{Escreve a respeito LEONARD WHITE:}

"The view that government corporations have so distinct and separate a function that coordination of policy is irrelevant will hardly bear examination. To depend upon personal relations with the President is inadequate especially as the number of corporations increases... To place each of these corporations "within" one of the major departments of government, clearing on major policy with the secretary of the department while retaining a substancial degree of operating freedom, does create an organic relationship which ensures harmony of general program and responsiveness to the policy of the party in the power. Essential coordination of policy is thus guaranteed by the type of relationship exemplified in the Inland Waterways Corporation".

A tendência dominante no direito norte-americano é pois no sentido do enquadramento das emprêsas públicas no executivo por meio eventualmente de uma união pesssoal, como a direção da emprêsa exercida pelo titular de uma secretaria de Estado.

A completa autonomia das emprêsas públicas assegurada inicialmente tinha levado à uma política izolacionista das diversas entidades descentralizadas. Ràpidamente a reação se fêz sentir. Diversas leis, de 1935 a 1945, vieram submeter as contas das emprêsas estatais ao Bureau of the Budget. A seguir, as modificações do capital social ficaram sujeitas à aprovação do Congresso e as normas do serviço público (civil service) passaram a ser aplicadas às emprêsas públicas de acôrdo com o Ramspeck Act. Um plano de reorganização de 1939 subordinou tôdas as emprêsas públicas, salvo a Tennessee Valley Authority e a Federal Deposit Insurant Corporation, a secretarias de Estado. Enfim, com o Government Corporation Control Act de 1945, as emprêsas públicas perderam a sua autonomia fiscal.

Vemos pois que a evolução realizada foi no sentido da introdução das emprêsas nas secretarias de Estado, restringindo-se-lhes a autonomia e sub-

(5) Obra citada na nota anterior, p. 119. 
metendo-as aos mesmos contrôles parlamentos que os outros departamentos públicos.

C. H. PritchetT, em artigo intitulado $O$ Paradoxo das emprêsas públicas escreve que a lei de 1945 é o último passo na luta de 10 anos travada contra a autonomia das emprêsas públicas. Assim se completou o trabalho de eliminação dos traços característicos que fizeram das emprêsas públicas instrumentos úteis para a realização dos grandes empreendimentos econômicos e sociais. A fiscalização imposta significa que, para o bem ou para o mal, a experiência americana das emprêsas públicas autônomas está substancialmente finda. (6)

Devemos ressaltar todavia que, se verdadeira, a afirmação de PRITCHETT não representa opinião pacífica nos próprios Estados Unidos. LEONARD WHITE dela diverge ao dizer que, nơ mundo de amanhã, tanto a emprêsa pública como a sociedade de economia mista podem ser destinadas a ter um papel grandioso. "Government corporations and mixed enterprises may be destined to play a significant role in the changing world of the future". (7)

A tendência dominante nos Estados Unidos é todavia no sentido de restringir a autonomia das emprêsas públicas sacrificando a sua flexibilidade à unidade que o govêrno quer garantir. Desaparecidas as três liberdades, pouco resta da autonomia das emprêsas. As sucessivas fiscalizações prejudicam o andamento rápido dos negócios das emprêsas.

Já tivemos a ocasião de dizer a respeito:

"A tendência atual do direito administrativo é dominada pelos princípios de padronização excessiva. Já se falou na desautarquização das autarquias. Transformaram-se as autarquias, as emprêsas públicas e as sociedades de economia mista em simples repartições públicas, perdendo a sua iniciativa e o seu senso de responsabilidade própria sob o pêso esgotante dos múltiplos contrôles. Já vimos que, tanto na França como nos Estados Unidos, as Emprêsas públicas desapareceram devido à excessiva fiscalização, integrando-se nos ministérios e de sociedade comercial só conservando a nome".

Com o enquadramento das emprêsas no executivo, o contrôle parlamentar se torna o que êle é em relação aos diversos departamentos públicos, havendo apenas uma influência maior na nomeação dos diretores das emprêsas para a qual se exige geralmente a aprovação do Senado.

São êstes os princípios gerais que regem a matéria.

\section{BIBLIOGRAFIA}

FREDERIC A. OGG and P. ORMAN RAY, Introduction to American government 9 th edição, N. York, 1948.

LEONARD D. WHITE, Introduction to the study of public administration, 3rd ed., 1951.

MAURICE S. CULP, Creation of government corporation by the national government, in Michigan Law Review, vol. 33 n. ${ }^{\circ} 4$, p. 473 - 511:

(6) PritchetT, in American Political Science Review, 1946, p. 509.

(7) LeONARD White, op. cit., loc. cit. 
VAN DORN, Government owned corporations, 1926.

DAVID LILIENTHSL 86 ROBERT MARQUIS, The conduct of business entreprises by the federal government, in Harvard Law Review, Fevereiro de 1941, p. 550.

American Government - Government in Action - by Robert E. Keochane, Mary P. Keohane and Joseph D, McGoldrick - Em 215 published for the United States Armed Forces.

\section{SUMMARY}

(1) U.S. administrative law recognizes two major forms of decentralization: independent establishments, and government corporations.

(2) Commissions, which form the greater part of the independent establishments, are principally employed when deliberative or consultative functions are called for. Their functions range widely.

(3) Initially employed as mixed enterprises for fiscal purposes, government corporations later extended their functions. At first created by the Legislative, later by the Executive. Their mushroom growth during the New Deal, and the appearance of different legal problems in connection with them.

(4) There also exist limited companies belonging to States, as well as state corporations.

(5) Each enterprise has its own character and structure determined by the bill establishing it.

(6) Three main reasons for public enterprise in the United States: (a) the need for easy credit in time of depression; (b) the need to solve urgent defense problems; (c) the need for the provision of services which can only be undertaken by the State.

(7) With regard to gpvernment corporations, distinction should be made between mixed enterprises and public enterprises proper, although there is no widely accepted definition of a public enterprise.

(8) It is recognized that the superiority of public enterprises over public departments proper lies in their flexibility and commercial efficiency.

(9) However, the view is that government corpotations should be more strongly coordinated with general government policy. To-day, government corporations have lost much of their original autonomy.

Não é bastante ajudar as pessoas a aprenderem "o que" fazer e "como" fazer. E' também importante ajudá-las a compreender "porque" fázem e a captar o sentido do que quer que seja que estejam aprendendo.

Staff Development - Training Manual n. 6 - Federal Security Agency - U.S.A. 